\section{A PERSPECTIVA DO "NÓS" HEGELIANO NA CRÍTICA DE MARX À ECONOMIA POLÍTICA}

\author{
Thiago de Lima \\ Graduando em Filosofia - UnB \\ Murilo Santos \\ Graduando em Filosofia - UnB
}

\begin{abstract}
Resumo: O fio condutor deste trabalho serão os pontos comuns contidos dentro da Fenomenologia do Espírito, de Hegel, e da juventude à maturidade das obras de Marx. Basicamente, procuraremos abordar a influência da perspectiva do "Nós" hegeliano contido na Fenomenologia do Espírito no projeto de crítica aos pressupostos da economia política empreendida por Marx, e como o aspecto da mediação sócio histórica proposta por Hegel determina os marcos do projeto filosófico marxiano.
\end{abstract}

Abstract: The guiding thread of this work will be the common points contained within Hegel's Phenomenology of Spirit, and youth at the maturity of Marx's works. Basically, we will try to address the influence of the Hegelian "We" perspective contained in the Phenomenology of the Spirit in the project of criticism of the presuppositions of the political economy undertaken by Marx, and how the aspect of the socio-historical mediation proposed by Hegel determines the milestones of the Marxian philosophical project.

Primeiramente, procuraremos fazer uma incursão pela introdução e o primeiro capítulo da Fenomenologia do Espírito com o intuito de introduzir a perspectiva do "Nós" contida nestes textos. A importância desta se faz vital para o projeto de crítica à economia política proposto por Marx, pois introduz a noção de mediação social.

No segundo momento, procuraremos mostrar como o "Nós" hegeliano influência a crítica de Marx às concepções econômicas legadas pela economia política clássica. Marx se apropria da perspectiva normativista proposta por Hegel para criticar os pressupostos da economia clássica, sobretudo as considerações desta ciência acerca da propriedade e trabalho. A economia política considerou estas categorias de maneira geral e descontextualizada. O intuito de Marx é compreender tais categorias como historicamente determinadas e socialmente mediadas, compreendendo que os economistas desconsideraram as determinações sociais e históricas que permeiam o trabalho e seus produtos. A ideia de Marx é fornecer melhores bases para se compreender a dinâmica político-econômica a partir de um ponto de visto histórico, e neste sentido o "Nós" da Fenomenologia do Espírito cumpre papel central neste projeto, pois se encontra desde sempre imerso no processo que constrói as variadas formas da consciência.

Hegel através de seu conceito de experiência abandona a perspectiva estranhada da epistemologia moderna, pois esta, sobretudo com Kant aparta o conceito da Intuição, considerando os dois como enfaticamente separados resultando isso no estranhamento, ou seja, uma relação de exterioridade impenetrável no objeto.

$\mathrm{O}$ autor pretende inicialmente superar a dominação presente no conceito puramente cientificista de natureza e como decorrência disto trará à tona a contemplação participativa, já que de certa forma o sujeito pertence ao objeto no qual se deu a experiência. $\mathrm{O}$ conceito de experiência Hegeliano parte do pressuposto de que o método para ser verdadeiramente cientifico deve partir da liberdade do objeto.

No parágrafo 31 da Filosofia do Direito, Hegel ao tratar do método Dialético, específica esta noção da dimensão participativa que confere ao objeto certo grau de liberdade:

A dialética superior do conceito não consiste em produzir e apreender a determinação meramente como barreira e como contrário, mas sim, em produzir e apreender a partir dela o conteúdo e o resultado positivo, enquanto por essa via, unicamente, a 


\section{A PERSPECTIVA DO “NÓS” HEGELIANO NA CRÍTICA DE MARX À ECONOMIA POLÍTICA}

dialética é desenvolvimento e progredir imanente. Esta dialética não é, pois, um fazer externo de pensar subjetivo, mas a alma própria do conteúdo, que organicamente faz brotar os seus ramos e os seus frutos. [...] Considerar algo racionalmente não significa acrescentar de fora uma razão ao objeto e, por este intermédio, elaborá-lo, senão que o objeto é o por si mesmo racional; aqui é o espírito na sua liberdade, o ápice da razão autoconsciente, que se dá efetividade e se gera como um mundo existente; a ciência tem somente a tarefa de trazer à consciência esse trabalho próprio da razão. (HEGEL, 2006, p. 29-30).

Partindo desta noção, logo na Introdução da Fenomenologia do Espírito, Hegel encara a epistemologia moderna, em linhas gerais, como uma representação pouco refletida sobre o que seja em verdade o conhecimento, assim sendo, a noção natural de conhecimento da epistemologia moderna representa o conhecimento como se fosse algo fora de nós e, portanto, fora da verdade. Resumindo bem a crítica de Hegel, há o método de um lado, de outro está o objeto e por fim encontra-se o conhecimento representado fora de nós, fundado em uma instância neutra frente aos objetos e exterior à verdade, "o conhecimento é um meio passivo pelo qual a luz da verdade chega à nós" (HEGEL, 2012, p. 63).

Fazendo mais uma referência à Hegel, no parágrafo 41 da enciclopédia das ciências filosóficas se opondo a Kant, ele vai dizer que a necessidade de se examinar a faculdade de conhecimento antes do ato de conhecer, exigência esta da filosofia crítica moderna, cai no equívoco de "querer conhecer antes do próprio conhecimento", ou melhor, dizendo "sem entrar na água empreender a nadar", ou seja, a epistemologia moderna pretende conhecer o conhecimento, porém prescindindo do próprio conhecimento. (HEGEL, 1995,p. 109).
Quer dizer o autor que o ceticismo metodológico moderno, radicalizado por Kant, mitigou a ideia de pertença que o indivíduo têm em relação a um objeto e consequentemente a modernidade passou a encarar a verdade como algo suprahumano, separado da razão humana, algo inacessível não cognoscível humanamente.

Neste sentido o legado indiscutível da epistemologia moderna é a criação de uma barreira entre o que é o conhecer e entre o que é o absoluto e por decorrência não há aqui a possibilidade de acesso ao "Em Si" da coisa, sendo, portanto, isto o que é de mais representativo da representação natural, ou seja, a convicção na separação total entre o sujeito e o objeto.

Prosseguindo neste raciocínio para Hegel a epistemologia moderna representa o fim da concepção enfática de verdade do que é "Em si e para si", onde as coisas são reconhecidas objetivamente. A epistemologia moderna tem um propósito de subtrair da ciência um pensamento exterior, alheio ao indivíduo, seguindo sua própria convicção. A filosofia, então, só é feita pela convicção do indivíduo, porém isto não encontra sustentação, já que a justificação disso não se apresenta, pois não se leva em conta o contexto.

Desta forma, a experiência em Hegel pressupõe a imperatividade da apreensão da Coisa na maneira com ela se apresente em si e para si, "o padrão que ela mesma estabelece para medir o seu saber" (HEGEL, 2012, § 84).

Quer Hegel demonstrar que tanto partindo da convicção individual quanto da autoridade alheia está se partindo de elementos contextuais, que é justamente a consciência natural. Assim, em ambos os casos, são os elementos contextuais, os conceitos, que promovem a estabilidade, considerando que as 


\section{A PERSPECTIVA DO "NÓS" HEGELIANO NA CRÍTICA DE MARX À ECONOMIA POLÍTICA}

formas de vida conscientes são vidas instáveis que tem uma tendência a desenvolver uma dinâmica das transformações, políticas, epistemológicas, e históricas.

Não existe vida humana independente de conceitos, ou seja, para Hegel tudo é conceito e até mesmo na concepção individualista de apreensão da coisa de forma intuitiva da modernidade já são elas mesmas mediadas por uma compreensão anterior.

Posto que a estrutura do conceito seja a mesma da consciência de si (HEGEL, 2012, § 80), como as representações já detém uma aptidão para se tornarem conceitos, toda forma de vida por ser amparada conceitualmente, pode ser detida por uma normatividade conceitual. Vida Humana é aquilo que não pode ser enxergado apenas de fora, precisamos sempre da linguagem ou falando de outra maneira dos conceitos.

Portanto, não há o dado bruto absoluto, todas as coisas devem necessariamente ser mediadas por conceito, por linguagem. Tudo aquilo como o qual nos damos com a realidade já é linguagem, já é conceito.

É nesta perspectiva que Hegel intentando adentrar o padrão de medida imanente traz a tona o nós. A singularidade do nós se apresenta no modo como este desde sempre se encontra imerso no processo que constrói as variadas formas da consciência, o nós é um componente que testemunha a nova forma da consciência, como algo que é o resultado da negação determinada da forma de consciência que o antecede.
Sendo assim é clarividente para o nós que existe uma ambiguidade do novo objeto, conforme demonstrado no parágrafo $86 \mathrm{da}$ Fenomenologia:

[...] o primeiro objeto se altera para a consciência; deixa de ser o Em-si e se torna para ela um objeto tal, que só para a consciência é o Em-si. Mas sendo assim o ser para ela desse Em-si é o verdadeiro; o que significa, porém, que ele é a essência ou é seu objeto. Esse novo objeto contém o aniquilamento [nadidade] do primeiro; é a experiência feita sobre ele (HEGEL,2012, §86).

A influência da filosofia hegeliana no projeto de Marx pode ser entendida como a radicalização do projeto de crítica aos pressupostos adotados pelas chamadas ciências do espírito. Para Hegel, os filósofos recaíram inúmeras vezes no erro de "esquecer" a história dos conceitos de que tratavam, assumindo-os como categorias universais e imutáveis. O empirismo e o racionalismo, as duas maiores correntes filosóficas da modernidade, segundo Hegel, incorreram no erro de não considerar a mediação histórica das categorias de que tratavam, geralmente partindo do ponto de vista do indivíduo isolado ${ }^{1}$, na tentativa de assumir a perspectiva supostamente neutra das ciências naturais. Porém, para as ciências do espírito (a filosofia, sobretudo) tentar partir do horizonte "neutro" das ciências naturais é problemático, posto que os objetos das ciências do espírito são categorias dependentes de suas mediações históricas. Mais abaixo veremos como Marx trabalha a questão e esta afirmação ficará mais clara, mas aqui podemos citar conceitos como Estado, Sociedade e Deus, como categorias trabalhadas pela filosofia e que devem a história ${ }^{2}$ seus significados. A

\footnotetext{
1 Podemos ver esse apoio no indivíduo isolado em Descartes, onde o indivíduo pode colocar toda a tradição e as convenções sociais entre parênteses na medida em que isso lhe for conveniente (ou pelo menos o autor acredita que seja possível falar em um sujeito apartado das convenções em que ele se forma).

2 Quando falarmos em história aqui devemos ter em mente não a história como a descrição de fatos, mas as condições de vida, a organização social e etc, que são historicamente determinadas.
} 


\section{A PERSPECTIVA DO “NÓS” HEGELIANO NA CRÍTICA DE MARX À ECONOMIA POLÍTICA}

crítica dialética empreendida por Hegel consiste em desenvolver plenamente as categorias tratadas pela filosofia, compreendendo-as em sua relação intrínseca. A partir da perspectiva crítica de Hegel, Marx empreende seu projeto de crítica da economia política. O filósofo húngaro István Mészáros resume o interesse de Marx na obra de Hegel da seguinte maneira:

O discurso filosófico dominante - e politicamente mais relevante - da época tornava necessário alinhar-se com Hegel ou posicionar-se contra ele. Entretanto, desde o instante em que entrou nessas discussões, Marx introduziu algumas importantes restrições. Ao expressar suas reservas fundamentais em relação a Hegel e seus seguidores, ele também tentou preservar e aperfeiçoar a predisposição radicalizadora dos "jovens hegelianos"; assim, Marx definiu a meta emancipadora da filosofia como alfo que não apenas explorava plenamente o potencial crítico da abordagem do próprio Hegel, mas como necessidade emergente de ir além do que poderia conter dentro dos limites do sistema hegeliano (por mais esticados que fossem)." (MÉSZÁROS, 2002, p. 53).

É o potencial da crítica dialética o que é tão admirado por Marx no sistema hegeliano. Influenciado pelo sistema filosófico de Hegel, Marx deseja empreender uma crítica acerca do modo como a economia política clássica concebe o processo de produção capitalista. A crítica marxiana parte, assim como a hegeliana, das categorias da própria economia política com a pretensão de desenvolver todas as suas determinações, e mediações, a fim de contrapor como processo socialmente mediado aquilo que os economistas assumiram como universal e factual ${ }^{3}$. A perspectiva assumida por Marx na Contribuição da Crítica à Economia Política é a do conceito de "Nós" contido na Fenomenologia do Espírito. Essa perspectiva do "Nós" considera o objeto em sua liberdade frente ao sujeito, enquanto o mesmo é mediado socialmente e, por isso, condiciona a experiência do indivíduo desde o primeiro momento. Dizer que o objeto condiciona a experiência do sujeito significa que desde sempre o indivíduo se relaciona com o mundo circundante a partir de mediações históricosociais. A forma mais básica desta mediação é a linguagem. $O$ sujeito não se relaciona com o mundo a não ser por conceitos. Ou melhor, ele se relaciona com o mundo apenas a partir da mediação social e histórica que desenvolve estes conceitos. Posto isto, uma análise da realidade não poderia ser feita a partir da ótica do sujeito ${ }^{4}$, pois ele mesmo é um produto das condições e da época em que vive, ou desconsiderando as determinações recíprocas que os conceitos mantém entre si. Marx chama de robinsonada essa concepção que parte do indivíduo isolado, ou trata de conceitos sem considerar suas especificidades históricas. Os economistas querem falar das condições gerais

\footnotetext{
3 "Partimos dos pressupostos da economia nacional. Aceitamos sua linguagem e suas leis. Supusemos a propriedade privada, a separação de trabalho, capital e terra, igualmente do salário, lucro de capital e renda da terra, da mesma forma que a divisão do trabalho, a concorrência, o conceito de troca etc. [...] A economia nacional parte do fato dado e acabado da propriedade privada. Não nos explica o mesmo. [...] A economia nacional não nos dá esclarecimento algum a respeito do fundamento da divisão entre trabalho e capital, entre capital e terra. [...] ou seja, ela supõe o que deve desenvolver. Do mesmo modo, a concorrência entra por toda parte. É explicada a partir de circunstâncias exteriores. Até que ponto estas circunstâncias exteriores, aparentemente casuais, são apenas a expressão de um desenvolvimento necessário, sobre isto a economia nacional nada nos ensina.” (MARX, 2010, p. 79).

4 Podemos aqui citar Hobbes e Locke como filósofos que partem do ponto de vista do indivíduo isolado. Dizer isto significa que estes autores antecipam no que eles mesmos chamam de "estado de natureza" - estágio em que os seres humanos vivem em estado de completa liberdade e sem a existência de um poder supremo que delimite a mesma - $o$ que só poderia ser concebido em sociedade, como a propriedade privada e o trabalho que produz propriedade privada, por exemplo.
} 
da produção na tentativa de criar uma ciência econômica universal e objetiva, mas no intento de atingir conceitos gerais eles formulam abstrações que levam consigo os traços característicos do sistema capitalista de produção, ou que não respeitam a diferença específica de outros modos e produção levando em consideração apenas as características comuns que estes têm com o modo de produção burguês.

Mas isto ainda não é tudo o que, efetivamente, preocupa os economistas nesta parte geral. Trata-se, antes, de representar a produção - veja por exemplo Mill diferentemente da distribuição, como regida por leis naturais, eternas, independentemente da História; e nessa oportunidade insinuamse dissimuladamente relações burguesas como leis naturais, imutáveis, da sociedade in abstrato.(MARX, 1987, p. 6).

Ao contrário, o que Marx deseja é desenvolver a economia partindo da análise da produção socialmente mediada, onde seus momentos determinam-se reciprocamente.

O objeto deste estudo é, em primeiro lugar, a produção material. Indivíduos produzindo em sociedade, portanto a produção dos indivíduos determinada socialmente, é por certo o ponto de partida. O caçador e o pescador, individuais e isolados, de que partem Smith e Ricardo, pertencem às pobres ficções das robinsonadas do século XVIII. (MARX, 1987, p. 5).

Para compreendermos a relação estabelecida por Marx entre a produção, distribuição, troca e consumo, e suas determinações recíprocas, devemos voltar nossa atenção para o que a economia clássica considerava acerca da mesma relação. Vejamos como, nas palavras de Marx, esta relação se dá:

[...] na produção, os membros da sociedade apropriam-se [produzem, moldam] dos produtos da natureza para as necessidades humanas; a distribuição determina a proporção dos produtos de que o indivíduo participa; a troca fornece-lhe os produtos particulares em que queira converter a quantia que the coube pela distribuição; finalmente no consumo, os produtos convertem-se em objetos de desfrute, de apropriação individual. A produção cria os objetos que correspondem às necessidades; a distribuição os reparte de acordo com as leis sociais; a troca reparte de novo o que já está distribuído segundo a necessidade individual, e finalmente, no consumo, o produto desaparece do movimento social, convertendo-se diretamente em objeto e servidor da necessidade individual satisfazendo-a no desfrute. (MARX, 1987, p. 7).

Assim explicam os economistas em sua teoria geral o processo de produção. $O$ que vislumbramos a partir desta descrição é o seguinte: a produção parte de um processo universal e imutável e o restante da economia oscila entre momentos sociais e individuais. A produção cria os produtos que satisfazem as carências dos indivíduos, independentemente de como se produzam. A distribuição encontrase como uma mediação entre os indivíduos produtores determinada socialmente, onde é entregue a parte que cabe a cada um na produção, e a troca aparece como um momento particular em que os indivíduos trocam sua parte da produção por aquilo que lhes aprouver. Finalmente, o consumo já se encontra fora da produção onde o indivíduo desfruta dos objetos da maneira que lhe apetece. A produção é um momento geral, a distribuição é social, a troca particular e o consumo puramente subjetivo. Agora vejamos como Marx desenvolve o conceito de produção na sua relação com os demais momentos do processo.

Marx deseja ver o processo de produção em suas determinações e mediações com relação ao todo. Iniciando pela mediação recíproca entre produção e consumo (itens que aparecem, em geral, apartados para a economia política 
clássica). Os economistas até consideram um tipo de consumo que se relaciona com a produção. O consumo produtivo é o tipo de consumo sem o qual a produção não pode se realizar. Este consumo é o consumo dos meios de produção e é colocado como um momento da produção, mas difere totalmente do consumo dos produtos. Ou seja, o consumo não tem relação alguma com a produção, a não ser quando a busca por novos produtos para consumo influencie o início da produção. Porém, há uma mediação recíproca entre a produção e o consumo (consumo "propriamente dito").

[...] ao mesmo tempo, opera-se um movimento mediador entre ambos. A produção, é mediadora do consumo, cujos materiais cria e sem os quais não teria objeto. Mas o consumo é também mediador da produção ao criar para os produtos o sujeito, para o qual são produtos. $\mathrm{O}$ produto recebe seu acabamento final no consumo. [...] Sem produção não há consumo, mas sem consumo tampouco há produção. (MARX, 1987, p. 9).

Aprofundando a relação entre produção e consumo, temos de perceber como a produção é influenciada em sua realização pelo consumo, e como o consumo é determinado pela produção em seu processo. Em outras palavras, como a produção é criada pelo consumo e como o consumo é criado pela produção.

O consumo determina a produção de uma infinidade de produtos e os coloca como objetivo da produção, por isto faz com que o ramo de produção que fabrica determinada mercadoria se torne cada vez mais eficaz na produção deste objeto. Desta forma, o consumo catalisa o processo de desenvolvimento das forças produtivas.

É o consumo que realiza plenamente o ato de produção ao dar ao produto seu caráter acabado de produto, ao dissolvê-1o consumindo a forma de coisa independente que ele reveste, ao elevar à destreza pela necessidade de repetição, a disposição desenvolvida pelo primeiro ato de produção [...] (MARX, 1987, p. 11).

Por outro lado, a produção condiciona o consumo determinando os produtos que podem ser consumidos e como podem ser consumidos. Nisto se evidencia a determinação histórica do consumo - visto pela economia como um momento puramente subjetivo - e da produção pensada por Marx a partir da perspectiva do "Nós". Aqui, a produção cria o modo e os produtos que podem ser consumidos, portanto cria um consumidor determinado, não um consumidor em geral, um consumidor autocrático como o sujeito liberal que se relaciona com os produtos sociais de maneira estritamente particular.

Um consumo sem objeto não é consumo. Assim, pois, a produção cria o próprio consumo neste sentido; mas não é somente o objeto que a produção cria para o consumo. Determina seu caráter, dá-lhe seu acabamento. Do mesmo modo que o consumo dava ao produto seu acabamento, agora é a produção que dá o acabamento do consumo. Em primeiro lugar, o objeto não é um objeto em geral, mas um objeto determinado, que deve ser consumido de uma certa maneira, esta por sua vez mediada pela própria produção. A fome é fome, mas a fome que se satisfaz com carne cozida, que se come com faca ou garfo, é uma fome muito distinta da que devora carne crua, com unas e dentes. [...] o próprio consumo, enquanto impulso, é mediado pelo objeto. A necessidade que se sente deste objeto é criada pela percepção do mesmo. [...] Portanto, a produção não cria somente um objeto para o sujeito, mas também um sujeito para o objeto. (MARX, 1987, p. 10).

Portanto, a produção media o próprio sujeito consumidor, e o sujeito consumidor media a produção. Entenderemos melhor como a 


\section{A PERSPECTIVA DO "NÓS" HEGELIANO NA CRÍTICA DE MARX À ECONOMIA POLÍTICA}

produção deve ser considerada uma categoria história refletindo sobre sua a relação com a distribuição.

Vimos que a distribuição aparece para os economistas como um momento social onde aos indivíduos são entregues as partes que lhe dizem respeito da produção. Porém, a distribuição, antes de ser distribuição dos produtos, é distribuição dos meios de produção. Portanto, a forma como uma sociedade produz é dependente de como esta partilhou a terra e os demais insumos de produção. Esta partilha é decorrência da fusão ou aniquilação de modos de produção anteriores ao vigente em uma determinada época. Esta distribuição dos meios de produção determina as formas de propriedade, a forma de trabalho, a distribuição dos produtos finais e com que intensidade estes são trocados no mercado.

[...] antes de ser distribuição de produtos, ela é: primeiro distribuição dos instrumentos de produção, e, segundo, distribuição dos membros da sociedade pelos diferentes tipos de distribuição, o que é uma determinação ampliada da relação anterior. [...] A distribuição dos produtos é manifestamente o resultado desta distribuição que é incluída no próprio processo de produção, cuja articulação determina. Considerar a produção sem ter em conta esta distribuição, nela incluída, é manifestamente uma abstração vazia, visto que a distribuição dos produtos é implicada por esta distribuição que constitui, na origem, um fator da produção. (MARX, 1987, p. 13).

Desta forma, percebemos que o processo concebido por Marx relaciona suas partes de forma orgânica, como momentos de um todo e como o autor deseja reformular as bases do pensamento econômico, reafirmando o papel da história para desenvolvimento das categorias por ela trabalhadas, da mesma maneira que Hegel ao criticar os fundamentos da moderna epistemologia.

\section{Referências bibliográficas}

HEGEL, G. W. F. Enciclopédia das Ciências Filosóficas. Trad. Paulo Meneses. São Paulo: Loyola, 1995;

Linhas fundamentais da filosofia do direito. Tradução de Marcos Lutz Müller. 2006. No prelo;

- Fenomenologia do Espírito. Trad.

Paulo Meneses. Petrópolis, RJ: Vozes, 2012;

MARX, Karl. Para a crítica da Economia Política. In: GIANNOTTI, José Arthur. Manuscritos econômicos-filosóficos e outros textos escolhidos. $4^{\mathrm{a}}$ ed. São Paulo: Nova Cultural, 1987.

Manuscritos econômicosfilosóficos. Tradução e apresentação de Jesus Ranieri $-4^{\mathrm{a}}$ ed. - São Paulo: Boitempo, 2010. (Coleção Marx - Engels);

MÉSZÁROS, István. Para Além do Capital: Rumo a uma teoria da transição. Tradução: Paulo César Castanheira, Sergio Lessa. Boitempo editorial, 2002.

RICARDO, David. Princípios de economia política e tributação. Tradução de Paulo Henrique Ribeiro Sandroni - São Paulo: Abril Cultural, 1982. 